\title{
Supporting decision-making for sustainable nanotechnology
}

\author{
Ineke Malsch • Vrishali Subramanian • \\ Elena Semenzin • Danail Hristozov • \\ Antonio Marcomini
}

Published online: 13 February 2015

(c) The Author(s) 2015. This article is published with open access at Springerlink.com

\begin{abstract}
Understanding how stakeholders manage risks associated with nanomaterials is a key input to the design of strategies and tools to achieve safe and sustainable nanomanufacturing. The paper presents some results of a study aiming firstly to inform the development of a software decision support tool. Further, we seek also to understand existing tools used by stakeholders as a source of capabilities and potential adaptation into decision support framework and tools. Central research questions of this study are: How is collective decision-making on risk management and sustainable nanomaterials organised? Which aspects are taken into account in this collective decision-making? And what role can a decision support tool play in such decision-making? The paper analyses 13 responses to a questionnaire survey held among participants in a meeting in October 2013 and a series of 27 semistructured telephone interviews conducted from January until April 2014 with decision-makers from mainly European industry and regulators involved in risk management and sustainable manufacturing of nanomaterials. Findings from the study on the social organisation of collective decision-making, aspects taken into account in decisions and potential role of decision support tools are presented.
\end{abstract}

\section{Malsch ( $\square)$}

Malsch TechnoValuation, Vondellaan 90, 3521 GH Utrecht,

The Netherlands

e-mail: malschtechnovaluation@xs4all.nl;

postbus@malsch.demon.nl

V. Subramanian · E. Semenzin · D. Hristozov · A. Marcomini Department of Environmental Sciences, Informatics and

Statistics, Ca' Foscari University, Dorsoduro 3246,

30123 Venice, Italy
Keywords Nanomaterials - Decision support · Risk management $\cdot$ Sustainable manufacturing

\section{Introduction}

The diverse applications of engineered nanomaterials (ENM) and nanoproducts have the potential to have important economic, environmental and societal benefits. The reaping of these benefits is contingent upon thorough assessment of its risks and impacts. However, risk assessment (RA) and life cycle analyses (LCA) are currently constrained by substantial knowledge and data gaps (Hischier and Walser 2012; Hristozov et al. 2012; Gavankar et al. 2012). An approach towards safe and sustainable nanomanufacturing is the integration of risk and impact analysis approaches with decision analysis (Linkov et al. 2014).

"Sustainable nanotechnology" has been advanced as a concept that can facilitate incremental nano-innovation even amidst significant data gaps (Subramanian et al. 2014a). An initial framing of "sustainable nanotechnology" can be extracted from emerging literature on safety and sustainability of nanomanufacturing, which advocates the integration of life cycle thinking, green nanotechnology, environmental and human health risk assessment analysis and management (Bergeson 2013; Dhingra et al. 2010; Mulvihill et al. 2011; Schulte et al. 2013). A sustainable nanotechnology framework based on decision analytic techniques can facilitate decision-making on nanomanufacturing in the following ways: (a) risk and impacts of various nano-enabled products can be compared, (b) risk management can be based on an integrated view of various risks and impacts and the trade-offs between them, (c) risks and impacts of nanomanufacturing 
can be minimised based on technically and economically optimal means, and (d) uncertainty estimation and sensitivity analysis can indicate the strength of evidence base and values on which decision-making is based.

The European Commission has recently funded a project on sustainable nanotechnologies (SUN, http://www.sunfp7.eu/) that aims to build tools in these areas that will be integrated within an overarching decision framework and software decision support system (DSS) for sustainable nanotechnologies (SUNDS). SUNDS is envisioned to be a user-friendly software for estimating risk due to ENM for workers, consumers and ecosystems in each life cycle stage, and evaluating the technical and cost-effectiveness of the available technologies and best practices in risk reduction.

A key task in SUNDS development is to understand the needs of its potential users (or stakeholders involved in risk management of ENM) in order to develop a tool that addresses user needs and supports them in achieving sustainable nanomanufacturing. Users can be involved at various stages of DSS development and extent of involvement, and in the role of developers, contributors and users (Black and Stockton 2009). While the majority of DSS involve stakeholders at the software prototyping stage, three arguments have been made to involve them from early development: (a) to capture accurately, within the DSS, problem formulations that are highly complex (including technical, managerial, regulatory and political components) and understood differently by various stakeholders, (b) to facilitate learning in an environmental management system through an environment of sharing and transparency and (c) to build trust in the output of the analysis through demonstrating its transparency and reproducibility (Black and Stockton 2009). There is a growing literature on expert perceptions and opinions related to risk assessment and management (Beaudrie et al. 2013, 2014; Besley et al. 2008; Corley et al. 2009). This can help in the development of the SUNDS tool by understanding how decision-makers perceive risk, and the limitations of existing risk assessment tools. However, to our best knowledge, there are no empirical studies on how stakeholders currently manage risks associated with ENM and act in the interest of achieving sustainable manufacturing. Therefore, a comprehensive user elicitation methodology starting from the early stages of DSS development is highly desirable.

The goal of the study described in this paper is to contribute to understanding (1) how two different stakeholders' groups (i.e. industry and regulators) make decisions on management of uncertain risks for ENM and sustainable nanomanufacturing, and (2) whether they are using or are familiar with frameworks and tools which could support them in such decision-making process. To this end, this paper discusses results of a questionnaire distributed among 58 representatives of research organisations and industry participating in a meeting resulting in 13 responses and a series of 27 semi-structured telephone interviews with regulators and industry decision-makers from Europe and third countries. Central research questions are:

- How is collective decision-making on risk management and sustainable nanomaterials organised? (discussed in Sect. 3.1)

- What aspects are taken into account in decision-making on risk management and sustainable manufacturing of nanomaterials? (discussed in Sect. 3.2)

- And what role can a decision support tool play in such decision-making? (discussed in Sect. 3.3, with subquestions:)

- How are decisions concerned with the safe production and use of nanotechnologies usually taken?

- What is the potential role of a DSS in supporting decisions concerned with the safe production and use of nanotechnologies?

- What other tools are available that can address the stakeholder needs in making decisions concerned with safe production and use of nanotechnologies?

\section{Methods}

\subsection{Overall study design}

The overall study design of the project is based on mental modelling theory. This is a psychological theory according to which individuals observe and act in the world based on more or less correct "mental models" they have formed of reality. The present article only reports on preliminary scoping stages of the project, so the discussion on mental models in this article will be limited to explaining the choice of the particular mental modelling approach that informs the study design in general and the questionnaires in particular. The main body of the article reports on interview results informing the design of the software decision support tool by risk assessment specialists participating in the project that will later become the expert model for comparison of different stakeholder groups' mental models.

Different concepts of mental models have been proposed, as well as different methods for investigating them (e.g. Morgan et al. 2002). Reviews of mental modelling theory distinguish between direct elicitation of mental 
models through diagrams sketched by respondents and indirect elicitation through text (interviews and other reports of decisions and actions) (Jones et al. 2011; Wood et al. 2012a).

Mental modelling theory has been applied widely in various contexts, and we are interested in its application in environmental management contexts. Jones et al. (2011) review its applications to natural resource management and list the following goals of applying mental models in that context: (a) to explore similarities and differences between stakeholders' understanding of an issue to improve communication between stakeholders, (b) to integrate different perspectives, including expert and local, to improve overall understanding of a system, (c) to create a collective representation of a system to improve decision-making processes, (d) to support social learning processes, (e) to identify and overcome stakeholders' knowledge limitations and misconceptions associated with a given resource and (f) to develop more socially robust knowledge to support negotiations over unstructured problems in complex, multifunctional systems. The "Carnegie Mellon" mental model approach (Wood et al. 2012a; Morgan et al. 2002) has been applied to environmental management case studies like climate change (Bridges et al. 2013; Roncoli 2006; Sterman and Sweeney 2007), water use (StoneJovicich et al. 2011) and flood management (Eisenman et al. 2007; McDaniels et al. 2008; Wood et al. 2012b).

Mental modelling theory has also been applied to ENM risk management. The International Risk Governance Council (IRGC) references the mental models approach implicitly in a white paper on nanotechnology risk assessment (IRGC 2006, p. 57) and in its overall risk governance framework (IRGC 2005). Morgan utilises expert elicitation derived influence diagrams to construct risk analysis modules for physicochemical characteristics, surface chemistry, uptake, fate and transport and toxicity (Morgan 2005). Further, mental modelling theory has also been extended to tool use contexts through the development of distributed cognition theory (Chandrasekharan and Tovey 2012; Hollan et al. 2000; Hutchins 1995; Nersessian et al. 2003). The Bayesian approach taken into account in this paper uses expert elicitation which is not the same thing as stakeholder elicitation (Money et al. 2012). To the best of our knowledge, a deeper account of stakeholders' mental models on ENM risk management, including one in the context of decision support tool use, is missing in the literature.

For the aim of the present study, a decision analysisbased mental models approach appears most suitable (cf. Wood et al. 2012a). Moreover, due to the nascent understanding of (interrelated) scientific and societal aspects of ENM risk management, we deem indirect elicitation of various aspects of risk management of ENM to be the more appropriate strategy for the present study. In this method, a (multidisciplinary) expert model or influence diagram is compiled that focuses on the influence of factor $\mathrm{X}$ on factor $Y$, investigates the probability or magnitude of this influence and compares expert with lay person knowledge. The original expert model can be compiled through a group modelling session, literature/peer review or other methods. Lay beliefs are solicited through semi-structured interviews that are mapped by the analyst onto the expert model followed by analysis of the mapping. In a third round, the frequency of occurrence of the lay beliefs in the target population are assessed through a survey with closed questions. The metrics to analyse lay beliefs are completeness, similarity and specificity. The outcomes of a study following this methodology should be an expert influence diagram, characterisation of lay mental models and comparison between the two (Wood et al. 2012a).

This method will be adapted for SUNDS design. Specifically, the study will not compare expert and lay mental models, but the mental models of different groups of experts in particular domains of risk management: risk assessment specialists developing the contents and criteria for the SUNDS tool and decision-makers in industry and regulatory sectors that attribute different weights to different types of criteria. These are not lay person stakeholder groups, but each has different (overlapping and complementary) expertise relevant to decisions on risk assessment and management. The final expert model in question will be the SUNDS decision framework rather than a drawn influence diagram, but the present article is limited to reporting on the scoping stages of the study. The expert model has not been developed yet.

Mental modelling has influenced the study design through its organisation in subsequent rounds of elicitation of stakeholder views. Each subsequent round includes a check of the elements of a mental model that have been identified in earlier rounds. This is done by asking mainly other persons in the same stakeholder group to comment on ideas proposed by their peers in the earlier round. The subsequent rounds of stakeholder view elicitation also include additional questions to generate a more complete picture of the mental models of different stakeholder groups and to inform the design of the SUNDS decision support tool. In the present article, completeness, similarity and specificity of representations of the collective decisionmaking process, aspects taken into account in decisionmaking and the potential role of decision support tools are compared between regulatory and industrial respondents.

\subsection{Analytical concepts}

The present article mainly reports results of an empirical study of stakeholders' views on risk management and sustainable manufacturing of engineered nanomaterials. 
Two main concepts are used to analyse these results: "ecosystem" and value chain.

\subsubsection{Ecosystem}

In the literature on innovation systems, the concept "innovation ecosystem" is widely used (cf. Jackson 2013). This concept is inspired by the term "ecosystem" used in the field of ecology. "Innovation ecosystem" is used to enable analysis of the economic circulation of material resources and human capital between the heterogeneous actors engaged in the innovation process (research organisations, companies, government bodies, etc.). The main issue is that an innovation ecosystem is a closed system, in which the output of one of the participating actors is used as input by one or more others and vice versa. Jackson (2013) stresses that the innovation ecosystem consists of two weakly coupled subsystems: the research economy driven by fundamental research and the commercial economy driven by the market.

Malsch (2014) has generalised the concept of "ecosystem" to three interconnected communities of actors engaged in regulation of nanotechnology and dialogue and communication on nanotechnology, respectively, in addition to Science, Technology and Innovation (ST\&I). She refers to literature on risk governance (Renn 2008) as well as innovation (Smits et al. 2010). The generalised "ecosystem"-concept enables analysis of flows of knowledge and arguments, and the development of agreement on responsible government of nanotechnologies rather than circulation of tangible resources as in innovation ecosystems. The concept allows for the analysis of the decisionmaking process on integral risk management and sustainable manufacturing of nanomaterials at a collective level by a heterogeneous set of actors (industry, government and other stakeholders). This is exactly the context for which the SUNDS decision support tool is being developed.

One could interpret the ecosystem as an expert model and analyse the completeness, similarity and specificity of the different stakeholders' representations of the ecosystem-part their company or organisation is active in.

\subsubsection{Value chain}

The term "value chain" was introduced by Porter (1985) to analyse how a firm adds value to resources that are acquired, transformed and marketed through primary activities in subsystems focusing on inbound logistics-operations-outbound logistics-marketing and sales services, supported by secondary activities including procurement, human resources management, technological development and infrastructure. The term "value chain" is currently used in a more generalised form. In this latter sense, value chains consist of clusters of industrial companies that consecutively add value to the same new technology incorporated in products. Stimulating the formation of such value chains is a central element of EU R\&D\&I strategy in the current European Union Research Funding Programme Horizon 2020. Nanofutures (2012) has developed a roadmap for nanotechnology based on a value chain approach. Seven value chains should bridge the gap between nanotechnology knowledge and successful commercialisation of nanoenabled products. The Nanofutures value chains are: integration of nano; functional fluids; lightweight multifunctional materials and sustainable composites; alloys, ceramics, intermetallics; structured surfaces; nano-enabled surfaces for multisectorial applications; infrastructure for multiscale modelling and testing; and cross-sectorial nontechnological actions. In the present article, a value chain for nanomaterials is constructed incorporating what industrial interviewees say about other R\&D and industrial companies they do business with or cooperate with. This value chain focuses on companies rather than technologies as in the Nanofutures roadmap (Nanofutures 2012).

The value chain can also be interpreted as an expert model and completeness, similarity and specificity of respondents' representations of the value chain their company is part of can be compared.

\subsection{Elicitation methodology}

To investigate decision-making on risk management and sustainable manufacturing of nanomaterials by a heterogeneous community of actors, we have developed a mental model based elicitation methodology comprising of four stages:

(a) Short scoping questionnaire distributed at SUN Project kick-off meeting, exploring the potential need for decision support tools

(b) Semi-structured telephone interviews of regulatory and industry sector representatives managing the risks and sustainable manufacturing of ENM, to identify key elements in their mental models

(c) User workshop to discuss and refine the preliminary MCDA-based conceptual framework of SUNDS developed based on the previous two steps, and

(d) Telephone interviews to elicit user weights for testing the finalised conceptual framework with SUN's seven case studies analysing the hazards and risks of different kinds of nanomaterials incorporated into products along these products' life cycles, from manufacturing until end of life

This paper reports results of the second stage of the study, but includes some discussion of relevant aspects of 
the first stage that are necessary to understand the questionnaire design and for comparing some results of both stages.

\subsubsection{Scoping questionnaire}

The first stage consisted of a questionnaire distributed at the kick-off meeting of the SUN project on 29-30 October 2013. Findings of this questionnaire survey have been reported elsewhere (Malsch et al. pending publication). It is mentioned here because this first stage enabled the design of the semi-structured interview questionnaire used in stage two and the selection of the relevant potential user groups for the decision support tool. The aim of the questionnaire in stage one was contributing to targeting the SUNDS decision support tool to the professional needs of the companies, research institutes and government bodies represented during the SUN kick-off meeting.

The questionnaire explored participants' decision-making on the risk management of ENM. This included aspects like the risk management decision processes and aspects taken into account, information sources, current use of software tools, self-assessment of decision and potential utility of decision support tools. The questionnaire was handed out to 58 participants in total, including scientific experts in different areas of risk assessment, large and small industry representatives and the organisers and support staff who were non-experts. Thirteen responses were received either on paper, online or by email. This constitutes a response rate of $22 \%$. The questionnaire is included in Appendix 1.

\subsubsection{Telephone interviews}

The second round consisted of 27 semi-structured telephone interviews with industrialists and regulators that were held in the period January-April 2014. There may be some overlap between the respondents to the questionnaire and the interviewees, because the questionnaire was anonymous. However, any overlap is limited to less than six persons (two from small- and medium-sized companies (SMEs) and four from large industrial companies). For the interviews, relevant decision-makers were selected from the larger population that had been identified in other projects as discussed below. Persons whose email addresses could be retrieved were asked for their cooperation in a semi-structured telephone interview of 30-45 min. The indicative questions were sent before the interview and the transcript was sent to the interviewee allowing him or her to make corrections or add information. The corrected transcripts were then analysed as background information to identify elements of mental models of decision-making regarding risk management and sustainable manufacturing of ENM. The questionnaire is included in Appendix 2.

Before selecting the interview candidates from industry, an estimate was made of the total size of the population of companies working with nanomaterials in Europe. For this, the following three databases were used. ObservatoryNano (2011) has identified 1,540 different companies that employed research activities on nanotechnologies and products incorporating nanotechnologies in Europe. Nanowerk's online database includes 2,106 commercial companies active in business to business activities in nanotechnology worldwide (Nanowerk 2014). This includes 307 nanomaterials suppliers, 305 in biomedicine and life sciences and 1,297 in products, applications, instruments and technologies. The Nanosafety Cluster compendium 2013 includes details of all partners in current and finished European Union (EU) funded projects on nanosafety (Nanosafety Cluster 2013). This includes at least 26 large industries and SMEs manufacturing or working with nanomaterials. For the purpose of our study, we can take the industrial population to consist of those companies presented in at least one of these databases with activities related to manufacturing, processing or marketing nanomaterials and products containing nanomaterials in Europe. It is safe to assume that this would amount to around 800 companies.

Most of the selected industrial interview candidates were chosen among the SUN partners, NanoSafety Cluster, our own contacts from other projects and contacts of the Dutch National Public Research Organisation TNO. This is because these companies have demonstrated interest in nanomaterials environment, health and safety (EHS) aspects, while this may not always be the case in the general population of companies working with nanotechnologies. In addition, the contact persons in the general databases are not always the persons in charge of nanosafety. For the present study, fourteen decision-makers in two associations and eleven companies producing nanomaterials, chemicals and materials, intermediary products and end products have been interviewed, in SMEs as well as large companies. These kinds of companies that are handling nanomaterials themselves are most likely to be interested in decision support for risk management and safe manufacturing of nanomaterials. For reference, a decision maker in a nano-instrument business was also interviewed. This company is not itself handling nanomaterials, but has expertise on nanoparticle measurement practices in companies that are handling these materials. The companies were headquartered in Belgium, Germany, Greece, Italy, UK and USA. Most companies were involved in SUN or other EU funded projects in the Nanosafety Cluster.

In order to estimate the size of the population of European regulators involved in risk governance of 
nanomaterials, we have made use of the database compiled by University College Dublin (NUID-UCD). This organisation has compiled a database of participants in nanotechnology-related events including contact persons for around 200 government organisations active in regulation of nanotechnology in Europe. This includes ministries, the European commission, notified bodies/inspectors/authorities and international organisations (cf. Malsch 2014). Some of the regulators included in this database have been approached as interview candidates. Other contact persons include the SUN Advisory board, the contacts list of the NANoREG EU project (www.nanoreg.eu) and contacts of other projects (e.g. NanoEIS www.nanoeis.eu, ObservatoryNano). Thirteen regulatory decision-makers including seven national and international policy makers, and six representatives of authorities and risk assessors have also been interviewed. The interviewees' expertise included chemicals safety, health/consumer protection and environmental protection. The interviewed persons came from Canada, Malta, the Netherlands, Switzerland, UK, the USA, European Union bodies and an international governmental organisation.

\section{Findings}

\subsection{Organising collective decision-making on risk} management and sustainable nanomaterials

In this section, the first research question is addressed: "how is collective decision-making on risk management and sustainable nanomaterials organised?" The 27 interview responses are analysed and discussed in Sect. 3.1.1. This is followed by the design of social maps summarising the organisation of collective decision-making at an abstract level in Sect. 3.1.2.

\subsubsection{Interview results}

During the interviews, respondents discuss their relationships with other actors they are cooperating or discussing with about risk management or sustainable manufacturing of nanomaterials.

One policy maker describes the overall regulatory system governing nanomaterials. This consists of four phases: production of nanomaterials, occupational health and safety, consumers and retail legislation, and legislation governing the end of fate and environmental impact of nanomaterials. Other regulators give more limited accounts of the particular regulatory subarea of their competence.

All thirteen regulators discuss the networks they operate in, resulting in the following overview of how the different regulatory bodies coordinate their work. At international level, the OECD secretariat coordinates the Working Party on Manufactured Nanomaterials (WPMN) consisting of member and observer states government representatives, international organisations (UNEP, WHO, ISO) and stakeholders. This secretariat also oversees the OECD Nanosafety programme, in which risk assessment researchers from these states cooperate, and liaises with international organisations including the Inter-Organization Programme for the Sound Management of Chemicals (IOMC), the Strategic Approach to International Chemicals Management (SAICM) and the International Organization for Standardisation (ISO).

At European level, the European Commission (EC) Directorates General (DG) Enterprise and Environment are co-responsible for the European Regulation on Registration, Evaluation, Authorisation and Restriction of Chemicals (REACH) and the regulation on Classification, Labelling and Packaging (CLP). Both DGs maintain links with the OECD WPMN, the European Chemicals Agency (ECHA), with EU Member States Competent Authorities in the Competent Authorities for REACH and CLP (CARACAL) Subgroup on nanomaterials (CASG Nano) together with industrial associations, NGO's and Trade Unions. The DG Health and Consumer protection (SANCO) manages three non-food scientific committees (SCENIHR, SCCF, SCHER) and maintains communication with the European Food Safety Authority (EFSA) food safety committee. DG SANCO has also organised stakeholder dialogue conferences called "Safety for Success" and feeds scientific knowledge into EU and international policy making bodies (CEN, OECD and ISO). It also maintains links with other DGs and national governments.

National policy makers participate in the OECD WPMN, the EC REACH annex discussion (CASG nano, CARACAL), the European NANoREG project and other projects in the European Nanosafety Cluster. They maintain contacts with toxicologists, national REACH coordinators, industry and other stakeholders at national level.

European and national authorities and risk assessors are engaged in a supporting role in several of the same networks as policy makers, but they also participate in other networks. ECHA coordinates the NanoMaterials Working Group NMWG that discusses scientific and technological questions relevant to REACH and CLP. This working group prepares recommendations on strategic issues. ECHA also coordinates the Group Assessing Already Registered Nanomaterials (GAARN), which builds consensus on best practices in assessing and managing the safety of nanomaterials under REACH. GAARN reports to ECHA-NMWG and to the stakeholders. National authorities and risk assessors maintain contacts with national ministries in their own country, the OECD WPMN, national risk assessment institutes in their own or other 
countries and expert panels on risk assessment research for nanomaterials. Three of the authorities and risk assessors also mentioned contacts with companies submitting dossiers for assessing chemicals safety.

Different types of regulators fulfil different roles in the decision-making process on risk management of nanomaterials. The OECD secretariat supports the decisions made by the OECD Council (ambassadors of member states). Most work is aimed at testing assessment methods of nanomaterials to ensure that test guidelines are relevant to EHS of nanomaterials. At EU level, policy makers at the DGs contribute to regular reviews of the REACH regulation and prepare proposals for revision of legal text and annexes for the political process of Committology (common decision-making by the Council and European Parliament, prepared by the European Commission). According to one policy maker, there is a strong organisational separation between units responsible for risk assessment and risk management as a result of the controversy over the BSE crisis (mad cow disease). Policy makers in risk management act as intermediaries between science and policy, economic and legal aspects. They formulate questions to scientific committees, asking them to propose a methodology for scientific assessment of risk nanomaterial or scientific elements of a definition of nanomaterial. The policy makers tend to propose different policy options in draft EU legislation to be decided upon by the politicians. Furthermore, DG Research and the (Horizon 2020) programme committee decide on funding priorities for risk assessment research. Other DGs including DG Environment, SANCO, Employment, etc., have very limited research budgets but may include a chapter at the end of a report on risk assessment flagging priority research needs. A policy maker considers it a problem that DGs and ministries responsible for research do not understand the regulatory process and research needs of DGs and ministries responsible for regulation. In his view, the research funding system should be reorganised in order to overcome divisions between disciplines. Because toxicologists lack knowledge of materials science, interdisciplinary work is needed as a basis for legislation.

National policy makers in EU member states ministries act as national REACH coordinator or competent authority for REACH and participate in the REACH Annex discussion aiming at development of requirements for testing and worst case scenarios for risk assessment of nanomaterials. At national level, they engage in the regulatory process and stakeholder dialogue according to one national policy maker, in order to ensure that the government can respond to conclusive evidence of hazards and risks. Another national policy maker is involved in regulating the environmental impact of nanomaterials including waste, waste water, end of fate and ecotoxicity.
Authorities are mainly involved in regulatory oversight. Their tasks include evaluation of companies' dossiers for chemicals registration (check whether risk assessment was performed in accordance with regulatory requirements), authorisation and inspection according to two interviewed authorities. This includes authorisation of biocidal products, chemicals registration and control of nanomaterials on the market in consumer products. They also fulfil advisory roles to regulators and disseminate information about the regulatory requirements and about nanomaterials. The interviewed risk assessors perform risk assessments of nanomaterials on the market and contribute to the development of OECD test guidance, but also advise on priorities in risk assessment of nanomaterials and basic research directions.

Experts also fulfil a role in the decision-making process. At the European Commission, their role is highly formalised: The EC requests a scientific opinion of an expert committee. This meets, sets up a working group and works on a scientific opinion during 1-2 years. The opinion is submitted for peer review and public consultation. The committee has to incorporate all comments or to argue why it does not include a particular comment. The outcome is in the words of one policy maker "a high-quality scientific opinion, cited worldwide, that contributes to the EU's political influence". At national level in at least one country, experts fulfil less formalised roles.

At OECD level, recent decisions relevant to nanomaterials are the OECD Council recommendation on nanomaterials of September 2013 that is not legally binding. The OECD Council Decision on Mutual Acceptance of Data (MAD) is legally binding for chemicals in general. The aim of the regulatory discussions at OECD level is to clear the way for nanomaterials to become part of this international system of legally binding agreements on the exchange of safety data. The OECD WPMN is preparing decisions on test guidelines and innovative test methods adapted for nanomaterials.

One policy maker reflects on the starting point for the REACH regulation around 2000: "The EU chemicals legislation should follow the same principles as the occupational health and safety legislation: make industry responsible for demonstrating the safety of substances on the market, instead of the government". The aim of the decision-making process engaging EU and national policy makers at EU level is "making REACH work for nanomaterials", in the words of another policy maker. To this end, the European Commission has introduced the recommendation on the EU definition on nanomaterials and promotes inclusion of this definition in REACH (as part of the review in 2014). This definition has partly solved the problem how to deal with the chemical identity of (nano)materials on the market, according to the first policy 
maker. The outcome of the regulatory review published by the European Commission in 2012 was to rewrite annexes to REACH. This "annex discussion" explores ways to deal with the chemical identity of these (nano)materials on the market, through a lex specialist or within current legislation. Another task of the European Commission policy makers is to prepare a proposal for an EU wide register for nanomaterials by end of 2014, early 2015 to the European Commission.

Authorities take decisions on individual nanomaterials and products based on risk assessment dossiers submitted by the companies. This varies from allowing the product on the market to banning it, depending on the result of the risk assessment. It may also result in identifying some risk with controls placed on manufacturer, such as prescribing Personal Protective Equipment (PPE) or engineering controls on exposure of workers during manufacturing, or imposing additional testing needs within a particular time frame after the stage of commercialisation.

The industry perspectives on collective decision-making on nanomaterials are remarkably different. Firstly, not all companies are the same and they fulfil different roles. A proposed categorisation of relevant companies from the mentioned databases of nanotechnology companies (ObservatoryNano, Nanowerk and Nanosafety Cluster) is: R\&D\&I, nanomaterials producer, chemistry and (other) materials, intermediary products, end products, marketing and waste processing. Large companies as well as some SMEs may cover more than one category in the value chain of nanomaterials. Three interviewed decision-makers in SMEs, one large industry respondents and two representatives of industrial associations discuss the whole value chain(s) the company is involved in. One SME participates in multiple value chains: from nanomaterials to end products in mechanical, automotive, ceramic, glass, chemical, textile, aeronautics, plastics materials and composite industries. Another is involved in a value chain encompassing a supplier of nanoparticle-based inks and users in the printed electronics industry and a third collaborates with two suppliers in a value chain, taking care of direct marketing of the company's own product enabled by nanomaterials. One large company has the whole value chain from nanomaterials via materials (pigments) to end products (ceramics and glass) in house and also sells (nano) materials to other industries. One association uses the concept value chain to identify barriers and solutions to get nanomaterials to the market, while another supports ongoing innovation and commercialisation of nanotechnologies in value chains and promotes safe and reliable advancement of the technological state of the art. Several interviewed decision-makers in companies only discuss part of the value chain: their clients and/or suppliers. Some of them also are concerned with the role of companies or organisations involved in waste processing.
Several industrial decision-makers explain who they discussed about nanotechnology with. These other organisations include their clients or supplier companies in order to inform these about the risk management of nanomaterials. One decision maker mentions submission of a dossier for REACH registration. Several industry decisionmakers have also informed insurance companies and investors about their risk management procedures, and some have been involved in risk assessment projects or risk management discussions in the framework of industrial associations. Two respondents have been involved in public dialogue or informing the public about nanomaterials.

\subsubsection{Designing the social maps}

Combined with the interviewer's background knowledge of the field (e.g. Malsch 2014), the results of the interviews allow for sketching social maps of the "ecosystems" of stakeholders involved in collective decision-making on risk management and sustainable manufacturing of nanomaterials. The present article uses the concept "ecosystem" in the wider sense as proposed by Malsch (2014) and explores how the innovation and regulatory ecosystems are discussed by stakeholders engaged in them. The interviewees in the present study do not explicitly mention the term "ecosystem", but they do mention other companies, experts or organisations that are involved in the collective decision-making process on sustainable nanotechnology. Most respondents only mention part of the ecosystem, while some express a more holistic perspective.

At a high, abstract level, this social map is represented in Fig. 1.

Figure 1 represents the collective decision-making process on what is generally called "responsible governance" of nanomaterials in which industry, regulators and other stakeholders participate. This includes risk governance and sustainable manufacturing of nanomaterials. What circulates in this process are legal requirements that are being formulated and decided upon during the stakeholder dialogue and political decision-making process on the top. This stage has been analysed in Malsch (2014) based on interviews with stakeholders engaged in that process. It is also discussed in the present study by interviewed policy makers who contribute to the preparation of political decision-making, which do not suggest significantly different outcomes from the other study. The result of this stage is legislation that is implemented by authorities in a four-phase regulatory process as discussed by policy makers, authorities and risk assessors interviewed in the present study. These authorities are responsible for overseeing the handling of nanomaterials during the industrial value chain in the third stage, discussed by industrial decision-makers in the present study. This value chain is driven by innovation and guided 


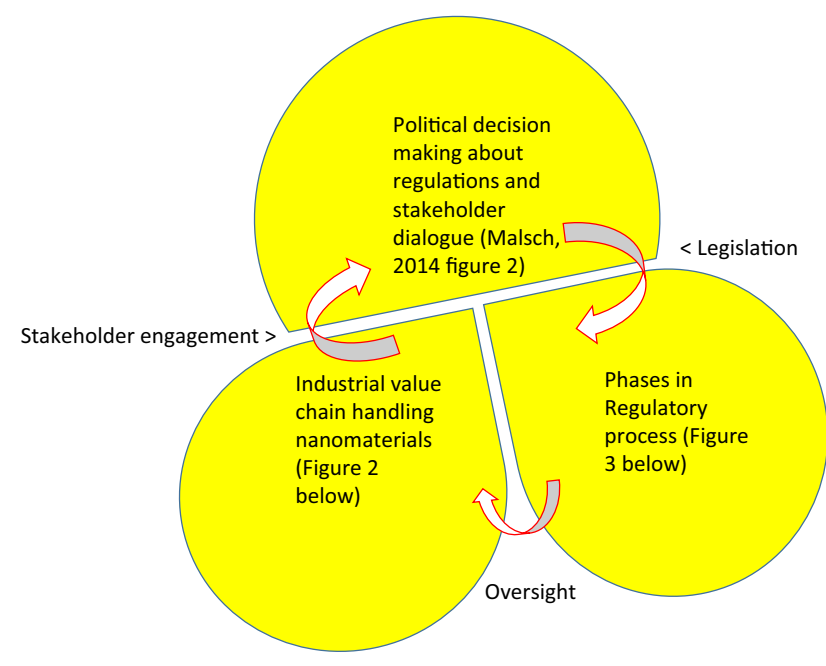

Fig. 1 Abstract social map of linked ecosystems of the political decision-making process and stakeholder dialogue about regulating nanomaterials, the industrial value chain handling the nanomaterials and the four-phase regulatory process controlling the handling of nanomaterials in all stages of the value chain. The three subsystems are connected through legislation, oversight and stakeholder engagement

by the current legislation that is in place. Innovation may result in new (nano)materials that call for new or adapted legislation. Industry representatives then participate in policy dialogue together with other stakeholders: it is a spiralling process.

Zooming in on the industrial part of the "ecosystem" a "value chain" from Research, Development and Innovation $(R \& D \& I)$ through nanomaterials production and their uptake in materials, intermediary and end products, marketing and waste processing has been identified in the databases of nanotechnology industry discussed above as well as in the interviews.

The industrial value chain is shown in Fig. 2. Supporting services including insurance, banks and instrument providers and industry and $R \& D \& I$ associations are not part of the primary activities in the value chain handling the nanomaterials themselves, but they do influence the management of nanomaterials as secondary activities within the value chain.

Within the general category "Regulators", three subcategories of organisations may be distinguished: national policy makers (ministries), bodies that implement policies (notified bodies, inspectors, authorities, etc.) and trans- and international bodies where regulations are coordinated [e.g. European Commission (EC), Organisation for Economic Cooperation and Development (OECD)] (cf. Malsch 2014; Fig. 3). Another categorisation that emerges from the interviews in the present study is by policy area (Chemicals safety, occupational health and safety, health/consumer protection and environmental protection).
Figure 3 depicts the four distinct regulatory phases gleaned from the interviews with regulators on risk management of nanomaterials. The phases are characterised by subsequent steps that should be taken in the regulatory process governing nanomaterials. The first phase is occupational health and safety legislation governing the protection of workers handling nanomaterials in research or production. The second phase is chemicals regulation governing nanomaterials in products on the market. The third phase aims to protect consumers and to regulate retail of products with nanomaterials inside. The final phase governs the waste disposal and environmental impacts of nanomaterials. Some interviewed regulators sketch the whole regulatory system, while others tend to focus on the particular legislation they are responsible for (chemicals, health and consumer protection or environment and waste, respectively).

\subsubsection{Conclusion: How is collective decision-making on risk management and sustainable manufacturing of nanomaterials organised?}

The interviews suggest that risk management and sustainable manufacturing of nanomaterials is primarily an issue handled by national governments and transnational (EU) and international (e.g. OECD) governmental organisations. Most of the organisations engaged in policy making and oversight mentioned by respondents are public bodies and these organisations also maintain most working relations with each other. These governmental organisations are joined by experts (including risk assessment specialists and staff of authorities) and stakeholder representatives (including industry associations) mainly during the political decision-making process resulting in new or adapted legislation. There is not one comprehensive law covering all nanomaterials, but the life cycle of nanomaterials is divided in four phases, each covered by different types of legislation as depicted in Fig. 3. Authorities and risk assessors are engaged in oversight of the compliance of companies to one of these legislative domains. The industrial decision-makers interviewed in this study discuss a much more limited scope of decision-making, where the current legislation and requirements by clients, governments and other stakeholders tend to be taken as given and the perspective is more dominated by their company's place in a particular value chain and the internal structure of the company.

The elements of the mental models of the value chain (Fig. 2) that are mentioned by the respondents indicate that completeness and specificity of the representation vary between individual industry respondents, but that there is no significant difference between SMEs and large companies. The parts of the value chain discussed are similar 


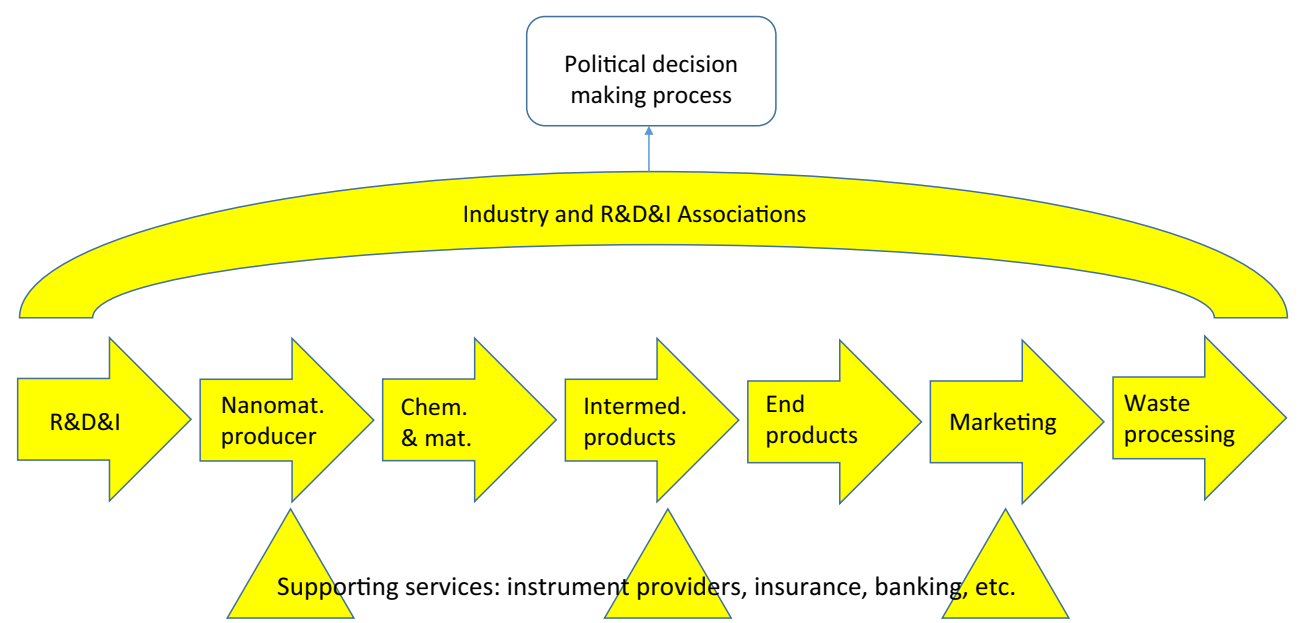

Fig. 2 Industrial value chain of companies handling nanomaterials. In this figure, R\&D\&I means research, development and innovation centres or consultants developing new nanomaterials, products and processes. Nanomat. producers are companies that manufacture nanomaterials, chem. \& mat. refers to companies that incorporate nanomaterials in chemicals and (composite) materials, intermed. products refers to companies that incorporate these materials in intermediary products they sell to other companies, end products to companies that manufacture products sold to consumers or other endusers, marketing refers to companies that sell the products and waste processing to organisations involved in recycling, incineration or deposition of waste containing nanomaterials
Fig. 3 Phases in the regulatory process of nanomaterials from European Union regulatory perspective. DG means Directorate General of the European Commission. It is the European equivalent of a government ministry. Occupational H\&S means Occupational Health and Safety. ECHA is the European Chemicals Agency and REACH the European Regulation on Registration, Evaluation, Authorisation and Restriction of Chemicals
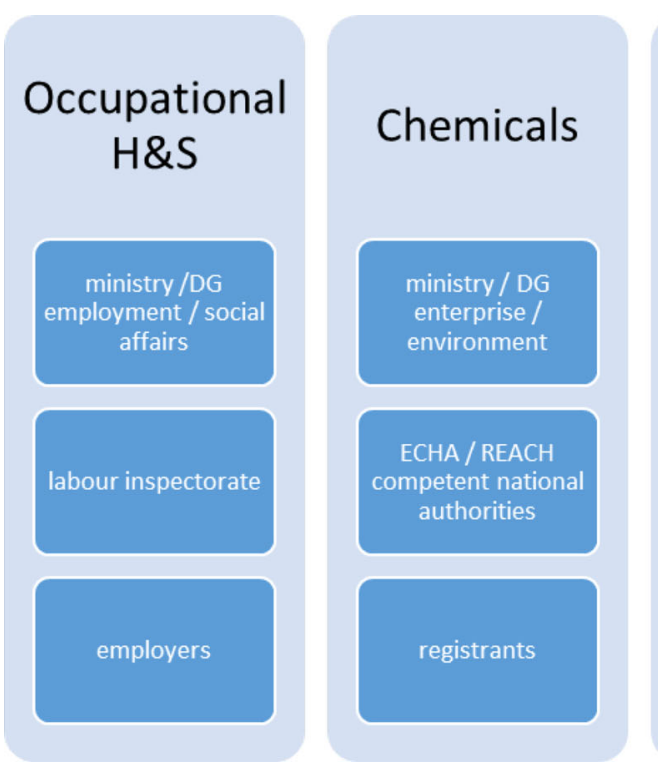

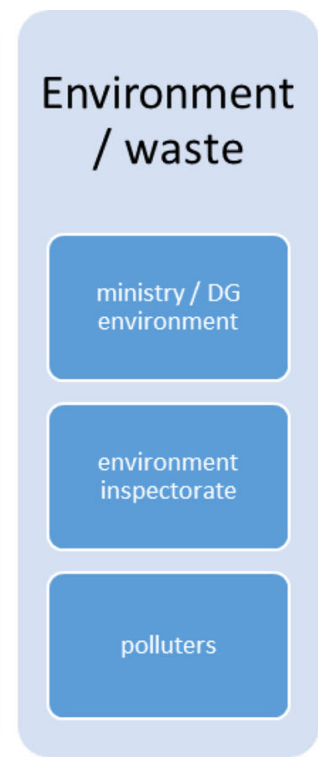

(supplier-company-client plus links with secondary companies and associations).

The representation of the regulatory process (Fig. 3) by the interviewed regulators is significantly more complete than the industrialists' representations, although there is considerable variation between individuals. Industrial respondents mainly refer to the authorities and their requirements for $\mathrm{REACH}$ registration. Among regulators, only one respondent discusses the whole four-stage process. The representations by regulators are similar to other regulators. Specificity varies between individuals.

\subsection{Relevant aspects in decision-making}

The second research question is: "which aspects are taken into account in decision-making on risk management and sustainable manufacturing of nanomaterials?"

The starting point for collective decision-making on risk management as well as sustainable manufacturing of nanomaterials should be agreement on a common definition of nanomaterials. Five policy makers and five representatives of authorities or risk assessors as well as three representatives of SMEs, three large industry 
representatives and one representative of an industry association discussed such definitions.

For two European regulators, the EU recommendation of a definition of nanomaterials represents the required common definition. Others including industrialists as well as regulators observe a splintering rather than harmonising trend in the international discussion on definitions and nomenclature for nanomaterials, both at global level and inside the EU. Inside the EU one regulator discusses an ongoing controversy between countries that emphasise hazards of nanomaterials and countries that emphasise risks of nanomaterials (hazard $\times$ exposure). The diversity in interviewees' views on what is a nanomaterial is in line with the EC JRC report on the current status of definitions of nanomaterials in preparation for the review of the EU definition foreseen by end of 2014 (Rauscher and Roebben 2014).

The questionnaire responses resulting from stage one of the study suggest a preliminary list of aspects that should be taken into account in decisions on risks management and sustainable manufacturing of nanomaterials and that could be integrated in the SUNDS DSS (see the table in Appendix 2). Besides discussing more general aspects they take into account in their own decision-making, the interviewees in stage two comment on this list, adding to it and attributing values to individual aspects suggested in the first stage. These aspects include environmental, health and safety aspects analysed in Sect. 3.2.1. They also include aspects relevant to sustainable manufacturing analysed in Sect. 3.2.2 including environmental, economic and social aspects. ${ }^{1}$

\subsubsection{Risk management aspects}

As has been argued in Sect. 3.1, reflection on the aspects that should be taken into account in risk management of nanomaterials is more a concern for regulators than for the interviewed industrial decision-makers. Two types of regulators are involved in decisions on risk management of nanomaterials: policy makers on a strategic level and authorities and risk assessors on a more practical implementation level. Industrial decision-makers tend to take the regulatory requirements as give, but may consider other aspects in their decision-making.

Policy makers supporting political decisions take both political and scientific aspects into account. As one interviewed policy maker explains, their role is an "intermediary between science and policy, economic and legal aspects". The proposed measures should be integrated in and compatible with the existing regulatory frameworks for

\footnotetext{
1 They also commented on desirable technical features of the proposed tool, but that goes beyond the scope of the present article.
}

either protection of employees, consumers or the environment, depending on the government department the policy maker is working in. In the words of another policy maker, they should "ensure that the government can respond to conclusive evidence of hazards and risks".

In the absence of scientific evidence, an interviewed policy maker explains that European authorities consider worst case scenarios as the basis for the risk assessment of nanomaterials. There is international discussion about developing common test methods covering physicochemical properties, ecotoxicology, genotoxicology and toxicokinetics according to another policy maker. These test results are required to be included in dossiers submitted to the authorities by companies.

Respondents involved in risk management decisions on nanomaterials in regulatory bodies feel that, in any case, environmental, health and safety aspects should be taken into account in these decisions. Several regulators responsible for environmental protection state that environmental aspects including LCA and environmental risk management are relevant to them. Other regulators responsible for protecting workers, consumers or public health say that they do not really need to take these environmental aspects into account. These aspects can be identified through companies' own tests or from literature and other sources of information.

The main issue for the interviewed regulators is the current lack of reliable risk assessment data including data on hazards and on exposure during the value chain of products with nanomaterials. This inhibits the possibilities for evidence-based decision-making on risk management. Respondents' opinions differ on the best strategy to overcome this. Some insist on the need to generate robust data enabling quantitative risk assessment. Others favour the exploration of "qualitative approaches" or "alternative methods" looking for similarities between untested nanomaterials and nanomaterials for which test data are already available.

A decision maker on risk management of nanomaterials in a large company takes into account nanomaterials characteristics, inhalation toxicity and life cycle assessment. Other industrial respondents also mention some of these aspects. According to one large and one small company respondent, the precautionary principle governs occupational health and safety for employees of the company as well as other companies down the value chain. Regulatory requirements may be balanced with costs to determine the focus of risk assessment in another SME. Several decision-makers in industry state that environmental aspects including LCA and environmental risk management are relevant to them. Two company decisionmakers remark that environmental aspects may only be relevant to them if nanomaterials can (in the future) be 
released from products during their life cycle, which is not clear from available data.

Respondents involved in risk management decisions on nanomaterials in large and small companies take, environmental, health and safety aspects into account in these decisions. For one SME, this will only be necessary when the company will decide on investment in scaling up production of nanomaterials. For a large company, this may be required if the company decides to handle nanomaterials.

It appears that determining the aspects that should be taken into account in risk management and how to ensure the availability of good quality data are mainly issues for regulators. Industrial respondents mainly need to consider risk management aspects when they change manufacturing processes or in response to external demands for data or other information. Then, the aspects taken into account are prescribed by regulators or demanded by other stakeholders such as clients or civil society organisations.

\subsubsection{Relevant aspects in decisions on sustainable manufacturing}

Sustainable manufacturing is mainly discussed by respondents from large companies and one SME, but according to one respondent, at international level there is also some discussion about who should be responsible for life cycle aspects of nanomaterials in products: is this the sole responsibility of industry or could there be a role for governments as well? A number of aspects are important in decisions on sustainable manufacturing of nanomaterials, including economic considerations, the precautionary principle, sustainability and risks including toxicity, public acceptance and upcoming legislation, as well as potential benefits such as environmental benefits.

Particularly in all the SMEs participating in the interviews, the market potential and requirements are major drivers for manufacturing decisions, along with the company's own expertise and capacity. As one decision maker in an SME puts it: "the first question is: does the nanomaterial add value in manufacturing or the market, and the second is: can you make it safely enough? If the economic indicators are $\mathrm{OK}$, the societal indicators will fall in line. This is how most SME and start-up managers take decisions". Other decision-makers from SMEs are more nuanced and also mention broader considerations.

Opinions differ strongly on the usefulness and best way to take into account economic indicators. One regulator finds economic indicators clearly important, three do not. One industrialist considers them important for SMEs and start-ups. Another industry respondent remarks that economic assessment is normally embedded in company strategy setting and not linked to safety assessment. It is also deeply influenced by a company leadership's philosophy.

As for environmental benefits, a respondent from a large company stresses that "Tox beats Carbon", meaning that any consideration of potential environmental benefits of a product is only taken into account after the risks have been assessed and found to be acceptable.

Many respondents consider societal aspects to be important, in particular for controversial nanomaterials in Europe. Concerning regulation, a respondent from a large company considers it to be good to know which factors influence political decisions, but is not sure if these factors are always legitimate. One respondent from an SME remarks that "Online information on EC regulations $(\mathrm{REACH})$ for nanomaterial, in particular for CNT, should be clarified". Another considers that "the European approach puts too much emphasis on risks, and not enough on potential benefits of ENM". He also notes that the acceptance of read across and grouping-type approach by regulatory authorities is a problem. A decision maker in a large company perceives a lack of coordination in EU and globally between the three hubs where nanomaterials manufacturing takes place: the EU-in particular Germany - the USA and Japan. Cosmetics and food are the most active sectors for regulation according to him. A representative of an industry association notes that regulators regard nanomaterials as a special form of authorised materials on market.

Two policy makers and one respondent from authorities discuss policy and regulatory aspects. One policy maker expresses concerns about fragmented legislation trajectories: "nobody looks at the total picture". The Treaty of the European Union guarantees negligible risks, which calls for looking for worst case scenarios. Politicians answer the societal call by regulation, but dedicate insufficient funding for control of this legislation. He suggests making the regulation as innovative as the rest of the economy. Another policy maker also complains about limited resources for controlling a growing number of nanomaterials in the marketplace. In addition he criticises the governments of France and other European countries taking an "ultra-precautionary approach" where hazard alone is indicator of risk. In his view, compulsory reporting on nanomaterials should be founded on clear evidence of risk, and decisions should be taken at EU level. A respondent from an authority memorises differences in how socioeconomic assessments are incorporated in different European regulations. While REACH calls for socio-economic assessment of alternatives and assessment of the costs of replacing substances in its authorisation section, the negotiations on the EU cosmetics regulation were paralysed by a stalemate on nanomaterials and the required data. 
Therefore, this regulation is classical risk assessment based, without mentioning socio-economic implications.

Concerning societal aspects, two respondents from SMEs and two from large companies express concerns about the current negative tendency in the public debate about nanotechnology in Europe. One respondent from an SME describes the company's policy aiming at open but careful communication about nano in communication and sales engaging all staff. The problem he sees is that there is no time for a nuanced explanation in the market. According to him, many big companies struggle with the public image of nano. Another respondent from an SME perceives a campaign against nanomaterials in society. He is concerned that the fear of new things that is introduced by irresponsible NGOs (not stakeholders) will finish its innovation potential. Technical arguments are no match to emotional arguments in his experience. A respondent from a large company likewise believes that "some published risk issues are unwarranted. The quality of the data does not always seem to matter because publication of high-dose non-relevant or in vitro hazard data can become a perception issue". A policy maker similarly complains about "hit and run funding for research that is an incentive for toxicologists to create a hype in order to generate funding for their own technology, which is picked up by NGOs who push politicians to regulate". Another respondent from a large company notes that "currently there is a backlash in concerns about nanosafety. French venture capital investors that are backing investments in nanotechnology may shy away because of consumer concerns. This is a big issue that must be understood and addressed". On the other hand, a policy maker stresses that public attitudes are important on nanotechnology and that his government is grappling with how engagement can be made to work. A key aspect in this is getting industry to the table and to share knowledge and data. Likewise, another policy maker complains that competition and confidentiality prevent openness about test results and methodology.

Despite general agreement that societal aspects are important to sustainable manufacturing of nanomaterials, respondents express a lot of scepticism about incorporating societal indicators in general, and the three suggested indicators in particular in a software decision support tool. In the words of one large industry respondent: "overall, social perception of risk may be most important for success of nanotechnology, but the SUN project cannot make a decisive contribution here". Other respondents' doubts include the following. One issue is the wide divergence of social perceptions per country or region. A representative of an association considers that developing a decision support tool specific for nanomaterials may create the erroneous perception that all nanomaterials are the same. Another problem is the difficulty to grasp societal indicators and incorporate them in a tool. A solution suggested by one respondent is to include open questions asking users to fill in their expert judgement of relevant social aspects as part of a ranking. They should also be asked to give an explanation for their estimate, according to this respondent.

It appears from the interviews that the interest in sustainable manufacturing of nanomaterials is mainly present in some large and small companies, but that the aspects to be taken into account and how to measure them is still very controversial. The interviewed regulators and most SMEs appear to take a more reactive stance, responding to external incentives stimulating them to consider sustainable manufacturing.

\subsubsection{Comparison with one particular alternative framework}

The list of aspects that are taken into account in decisionmaking on risk management and sustainable manufacturing of nanomaterials presented here has been compiled in an empirical way by surveying and interviewing experts and stakeholders in the studied field. This bottom-up approach does not allow for determining the completeness of this mental model of decision-making on safe and sustainable nanomaterials. Therefore, this section compares the list of aspects proposed by the respondents in the present study to a similar list proposed by others in recent literature that is used as benchmark.

An interdisciplinary group of social scientists has proposed a "Framework for the Analysis of Nanotechnologies' Impacts and Ethical Acceptability" (Patenaude et al. 2014). Their approach combines traditional EHS aspects and ethical, legal and social aspects (ELSA), and interdisciplinary value judgements to determine weights of different aspects. It can be considered an MCDA model even if the term is not mentioned in the article. In contrast with their theoretical approach, we compile and test a set of aspects by soliciting suggestions by potential users of the SUNDS decision support tool. This improves the relevance of the tool to the real-life decisions users have to take. A potential disadvantage is that the SUNDS tool may overlook aspects that could be theoretically relevant, but are not currently taken into account by the decision-makers in companies and regulatory bodies. This can be addressed by comparing our list with the one proposed by Patenaude and colleagues in Table 1.

The main difference between the aspects proposed by the social scientists and by the interviewed decision-makers on nanomaterials is that the former exclusively consider effects of technology on humans, society and the environment. The decision-makers propose taking into account implications of economic, social and political trends that 
Table 1 Comparing aspects of SUN respondents with aspects of Patenaude et al. (2014)

\begin{tabular}{|c|c|}
\hline Patenaude et al. (2014) aspects & SUN respondents' aspects \\
\hline 1. Health & $\begin{array}{l}\text { Environmental, health and } \\
\text { safety/sustainability aspects }\end{array}$ \\
\hline \multicolumn{2}{|l|}{ 2. Life/death } \\
\hline \multicolumn{2}{|l|}{ 3. The environment } \\
\hline 4. The economy & Economic aspects \\
\hline $\begin{array}{l}\text { 5. The status and development of } \\
\text { scientific research }\end{array}$ & - \\
\hline 6. Freedom of choice & $\begin{array}{l}\text { Social aspects (social perceptions } \\
\text { of risks, factors influencing } \\
\text { political decisions, large } \\
\text { overview of normative frames) }\end{array}$ \\
\hline \multicolumn{2}{|l|}{ 7. Privacy } \\
\hline \multicolumn{2}{|l|}{ 8. Cohabitation (local-national) } \\
\hline \multicolumn{2}{|l|}{ 9. Cohabitation (international) } \\
\hline \multicolumn{2}{|l|}{$\begin{array}{l}\text { 10. Cultural representations of } \\
\text { the human being (identity- } \\
\text { nature-the person) }\end{array}$} \\
\hline- & $\begin{array}{l}\text { Technical aspects of the decision } \\
\text { support tool }\end{array}$ \\
\hline
\end{tabular}

are external to the R\&D\&I and manufacturing of nanomaterials on the acceptance in society of nanomaterials and products. This broadens the scope of the assessment to a co-creation perspective where developments in technology and society together cause societal and environmental impacts. This constitutes an addition to the technologypush perspective investigating implications of those nanomaterials and products on health and the environment which is common to both frameworks. Comparing the lists of potential effects, the social scientists take into account a more diverse list of potential effects on society. Some of these are not likely to be affected by industrial manufacturing of products incorporating nanomaterials, such as privacy, cultural representations of the human being or the status and development of scientific research, but may be relevant to other nanotechnologies, e.g. nanoelectronics or nanosensors.

It appears that those aspects are taken into account in collective decision-making on nanomaterials that examine the traditional EHS risks, life cycle aspects as well as indicators that allow for prediction of economic, social and political acceptance. The latter are not exclusively caused by the technical characteristics of nanomaterials, but also by autonomous economic, social and moral trends in contemporary society. In order to be relevant to the decision-making practice of the interviewed decision-makers, the SUNDS tool should incorporate a similar set of aspects as has come out of the interviews rather than the theorydriven set of aspects proposed by Patenaude et al. (2014).
Neither framework constitutes a complete mental model of EHS and ELSA aspects of nanotechnology, but Patenaude et al. include more detailed ELSA aspects, while the respondents in the present study include external trends that influence the viability of nanomaterials based products on the market. Both lists are to some extent similar, but not in the details. Respondents mention more specific aspects of EHS (toxicity, ecotoxicity, etc.) than Patenaude et al. who stay at a more general level.

\subsection{Decision-making and potential role of decision support tools}

The SUN project aims to develop a user-friendly software DSS, SUNDS, to facilitate industrial and regulatory decisions concerned with the safe production, handling and disposal of nano-enabled products. In order to do this, SUNDS will estimate the health and ecological risks and the environmental impacts along supply chains of industrial products containing nanomaterials and will suggest technological alternatives and risk mitigation measures to reduce these risks/impacts (including cost-effectiveness analysis). In order to design SUNDS to meet the expectations of its end-users, we aim to understand the users' needs. SUNDS is novel and has no analogue that the users have experience with. Therefore, in conducting these interviews, we did not expect to draw broader social implications from the responses towards the general role of DSS in collective decision-making. Instead, the interviews sought to answer the three sub-questions posed in the introduction.

1. How are decisions concerned with the safe production and use of nanotechnologies usually taken?

In the surveyed industrial companies as well as regulatory bodies, decisions on safe and sustainable nanomaterials are mostly taken in meetings involving own staff, where appropriate complemented by external experts. In smaller organisations, the decision-makers may be limited to the company management and some staff with relevant expertise. One SME respondent recalls internal meetings involving the company's $\mathrm{R} \& \mathrm{D}$ and production departments. In another SME, risk management decisions are taken in-house, while the company participates in risk assessment projects in collaboration with external partners. In a third SME, economic decisions are made by a small group of well-informed staff members (about the market and the company). The company also makes use of relevant information through participation in discussions organised by CEFIC or the EC and contacts with research centres. Another SME holds weekly discussions with all staff members during the product development phase and maintains continuous consideration of what materials to 
use. A fifth SME bases risk management decisions on own experience and in-house expertise in materials and occupational H\&S. They also take into account what they learn from external discussions with $H \& S$ experts and participation in national and EU nanosafety projects.

In larger organisations, a multidisciplinary group of experts may be involved in preparing the decisions. Respondents from three large companies discussed such multidisciplinary internal decision-making, while two large company respondents occasionally involve external specialists or participate in working parties that assist in putting together definitions nanomaterials organised by the JRC.

Literature, internet resources and test results that may be presented in dossiers as well as expert opinion tend to form the basis for decision-making according to the respondents from large as well as small companies. Some tests are done in-house, while others are done in projects together with research centres and other companies.

2. What is the potential role of a DSS in supporting decisions concerned with the safe production and use of nanotechnologies?

At the moment, DSS does not appear to be commonly used in risk management and manufacturing of chemicals and products as far as the respondents are aware. For nanomaterials, such tools are a topic of discussion, more among regulators than among industrial decision-makers. One SME has tried Stoffenmanager Nano and one large company uses in-house eco-efficiency tools for nanomaterials, while one SME uses a statistical tool to reduce the number of trials to valid outcome of risk assessment. One authority uses an online control banding tool, while two other regulators have heard about such tools being used by risk assessors or under development. Other large and small companies have heard about some tools used in industry for risk management and manufacturing of chemicals in general. In the future, there is not one single location where decision support tools might be used in the regulatory and industrial ecosystems where decisions are taken in regard to the safer and more responsible nanomanufacturing (see Figs. 1, 2, 3). Industrial respondents do not believe such future use will be soon, for a variety of reasons. One SME and one large company do not need it now, but may be interested in a tool when the company will invest in upscaling its production or start handling nanomaterials. Another SME foresees a need when nano is a commodity that is broadly used, which is not yet the case. A large company expects a need in 5-10 years, while another large company respondent fears that the tool may not be ready for prime time. A representative of an association sees mainly technical barriers questions to resolve are: (1) what model to use, (2) what information is needed, (3) software. However, several distinguished actors may be interested in using the tools for different purposes, and we elucidate these purposes in the paragraphs below.

The interviews suggest that an important use of DSS is in supporting assessors at companies and regulatory agencies in the process of registration of new compounds compliance with the requirements of chemical safety regulations such as the European Regulation on Registration, Evaluation, Authorisation and Restriction of Chemicals (REACH) and environmental regulations. This is the lower two levels in the second and fourth columns of Fig. 3. At least one large company has expressed interest in using DSS in portfolio management and/or safety by design engineering, while two of the interviewed decision-makers in SMEs have expressed interest in decision support on risk management before scaling up production. According to these and other respondents, the tool may be most useful for decision-makers in SMEs and large companies that are actually handling nanomaterials in the early stages of the value chain in Fig. 2: R\&D\&I, nanomaterials and chemicals manufacturing.

While most of the existing decision analytical tools for nanomaterials mentioned by at least one of the respondents (cf. Table 2 below) focus on either risk assessment/management or life cycle impact analysis, thus only partially responding to the above needs of their potential end-users, SUNDS is envisioned to conduct a more holistic NanoEHS evaluation. Specifically, the SUNDS results will cover health and ecological risks and environmental impacts, but will also suggest safer technological alternatives and risk mitigation measures, providing information on their costs. By tailoring this comprehensive assessment to regulatory frameworks, SUNDS could (1) strengthen collective actions between industries and regulators towards designing more sustainable nanotechnologies; and could be (2) useful in communication among industries and insurance companies about nano-EHS risks. Start-ups might also benefit because the results from applying the DSS could help raise awareness of nano-EHS issues that could prevent them from sunk investments.

According to some interviewed policy makers, they are not likely to use software decision support tools in preparing political decisions on regulating nanomaterials, especially not in the short term. ${ }^{2}$ According to other stakeholders, policy makers could benefit from tools that indicate whether they should take action on adapting regulation, or that support international harmonisation of nanomaterials regulations. It is not clear how SUNDS could support this use, and the possibility of having this feature in SUNDS has to be explored further.

\footnotetext{
${ }^{2}$ According to a reviewer, "this is not completely true. In one case, the US EPA has implemented a structure decision support methodology in order to prioritize research needs in several cases. So they developed a decision support method and tool to influence policy".
} 
Table 2 List of frameworks and tools as they are mentioned by industrial and regulatory respondents

\begin{tabular}{|c|c|c|c|}
\hline Category & Tools & $\begin{array}{l}\text { Mentioned } \\
\text { by Industry }\end{array}$ & $\begin{array}{l}\text { Mentioned } \\
\text { by Regulators }\end{array}$ \\
\hline \multirow[t]{4}{*}{ RA: control banding } & Stoffenmanager nano & $\mathrm{x}$ & $\mathrm{x}$ \\
\hline & Nanoriskcat DK (consumer products) & & $\mathrm{x}$ \\
\hline & $\begin{array}{l}\text { Online precautionary matrix, control banding tool: exposure situation, } \\
\text { tox }+ \text { uncertainties (Switzerland) }\end{array}$ & & $\mathrm{x}$ \\
\hline & $\begin{array}{l}\text { Annex XI REACH specifies alternative approaches, especially grouping, need } \\
\text { well developed read across method for nanomaterials, QSAR methods, } \\
\text { weight of evidence methods }\end{array}$ & & $\mathrm{x}$ \\
\hline \multirow[t]{5}{*}{ RA: Environmental RA } & $\begin{array}{l}\text { US Army system: scientific description behaviour nanoparticles in } \\
\text { environment, software for environmental fate and exposure: CAMSTEER/ } \\
\text { other }\end{array}$ & & $\mathrm{x}$ \\
\hline & $\begin{array}{l}\text { The International Uniform Chemical Information Database (IUCLID) system } \\
\text { REACH (European Chemicals Agency (ECHA) website) }\end{array}$ & & $\mathrm{x}$ \\
\hline & $\begin{array}{l}\text { The Inter-Organization Programme For The Sound Management of Chemicals } \\
\text { (IOMC) risk management toolbox chemicals }\end{array}$ & & $\mathrm{x}$ \\
\hline & $\begin{array}{l}\text { Predictive "scientific" tools: Ecological Structure Activity Relationships } \\
\text { (ECOSAR), DEREK }\end{array}$ & & $\mathrm{x}$ \\
\hline & Other risk assessment tools: EUSES & & $\mathrm{x}$ \\
\hline \multirow[t]{6}{*}{ RA: Human health RA } & $\begin{array}{l}\text { European Centre for Ecotoxicology and Toxicology of Chemicals ECETOC } \\
\text { TR } 93 \text { (2004), Tiered approach to risk assessment in chemical processes } \\
\text { could be extended to nanomaterials, but not Carbon Nanotubes (CNT) }\end{array}$ & $\mathrm{x}$ & $\mathrm{x}$ \\
\hline & $\begin{array}{l}\text { CONSEXPO for consumer exposure scenarios of chemicals in products } \\
\text { (National Institute for Public Health and the Environment (RIVM)), The } \\
\text { Netherlands }\end{array}$ & & $\mathrm{x}$ \\
\hline & $\begin{array}{l}\text { General Product Safety Directive: RAPEX (RAPid EXchange of information), } \\
\text { online risk matrix: chance x effect (European Union) }\end{array}$ & & $\mathrm{x}$ \\
\hline & IUCLID system REACH (ECHA website) & & $\mathrm{x}$ \\
\hline & IOMC risk management toolbox chemicals & & $\mathrm{x}$ \\
\hline & $\begin{array}{l}\text { Predictive "scientific" tools: OECD QSAR toolbox for chemicals risk } \\
\text { assessment (used by risk assessors): small models to assess mammalian } \\
\text { toxicity, calculate Derived no-effect levels (DNELs)/details on safety } \\
\text { measures, DEREK }\end{array}$ & & $\mathrm{x}$ \\
\hline \multirow[t]{2}{*}{ LCA } & $\begin{array}{l}\text { LCA tool (Saling et al. 2002), LCA, Carbon footprint, SEEBALANCE } \\
\text { (including social aspects), AGBALANCE (SEEBALANCE for agriculture). } \\
\text { Software for opportunity finding of new products, validated in expert } \\
\text { workshops }\end{array}$ & $\mathrm{x}$ & \\
\hline & Unspecified LCA software & & $\mathrm{x}$ \\
\hline MCDA & Unspecified MCDA tools & & $\mathrm{x}$ \\
\hline \multirow[t]{9}{*}{$\begin{array}{l}\text { Other tools/category unclear } \\
\text { from respondent's reference }\end{array}$} & $\begin{array}{l}\text { A statistical tool to reduce the number of trials to valid outcome of risk } \\
\text { assessment, }\end{array}$ & $\mathrm{x}$ & \\
\hline & $\begin{array}{l}\text { Experiment design software developed by the company } \mathrm{ABB} \text {, or used in } \\
\text { pharmaceutical industry }\end{array}$ & $\mathrm{x}$ & \\
\hline & An in-house kinetic model for formation of CNT & $\mathrm{x}$ & \\
\hline & $\begin{array}{l}\text { Planning tools for manufacturing, logistics, International Organization for } \\
\text { Standardisation ISO } 13,485 \text { system }\end{array}$ & $\mathrm{x}$ & \\
\hline & $\begin{array}{l}\text { Mathematical decision models and simulations for politics, management } \\
\text { decision support developed by economics faculties of universities/Economic } \\
\text { models (used by govt dept finance and competition) }\end{array}$ & $\mathrm{X}$ & $\mathrm{x}$ \\
\hline & Management software: administration, task and project management & $\mathrm{X}$ & \\
\hline & Decision tree spreadsheet giving recommendations for regulatory purposes & $\mathrm{x}$ & \\
\hline & Nanotechnology Industry Association (NIA)-Regulatory Monitoring Database & $\mathrm{X}$ & \\
\hline & $\begin{array}{l}\text { Projects developing online toolbox for nanomaterials safety assessment/ } \\
\text { regulatory compliance }\end{array}$ & $\mathrm{x}$ & \\
\hline
\end{tabular}


Table 2 continued

\begin{tabular}{|c|c|c|c|}
\hline \multirow[t]{6}{*}{ Category } & Tools & $\begin{array}{l}\text { Mentioned } \\
\text { by Industry }\end{array}$ & $\begin{array}{l}\text { Mentioned } \\
\text { by Regulators }\end{array}$ \\
\hline & $\begin{array}{l}\text { "Technical completeness check": administrative tools support decision on } \\
\text { registration number in REACH }\end{array}$ & & $\mathrm{x}$ \\
\hline & Predictive "scientific" tools: METEOR & & $\mathrm{x}$ \\
\hline & $\begin{array}{l}\text { UK, 2003: UK government had web-based tool for industry, focusing first on } \\
\text { exposure, second on danger: assisting them to sort out situations to be careful } \\
\text { or more lenient }\end{array}$ & & $\mathrm{x}$ \\
\hline & $\begin{array}{l}\text { Software decision support and formal approaches developed by UK Food \& } \\
\text { Environment Research Agency, expert opinion based }\end{array}$ & & $\mathrm{x}$ \\
\hline & Comprehensive environmental assessment (CEA)-based approach & & $\mathrm{x}$ \\
\hline
\end{tabular}

Some tools were mentioned by more than one respondent, but the list only includes these tools once

3. What other tools are available that can address the stakeholder needs in making decisions concerned with safe production and use of nanotechnologies?

The interviewees discuss several analytical tools for risk management of nanomaterials or conventional chemicals that are already available. They refer most often to the control banding (CB) tools Stoffenmanager Nano (van Duuren-Stuurman et al. 2012), NanoRiskCat (Hansen et al. 2013) and NanoSafer (Jensen et al. 2013). A main advantage of the CB tools is that they help the user identify worst case scenarios: if the tool indicates that a material presents no risk, it is presumably safe. Their main disadvantage is that none of them is validated and their robustness cannot be confirmed. Other tools that are discussed are the Quantitative Structure Activity Relationships QSAR (e.g. OECD QSAR toolbox for chemicals risk assessment), high throughput systems for combinatorial toxicology and statistical analysis, LCA-based tools [e.g. EcoEfficiency Analysis tool (Saling et al. 2002)], MCDA-based tools [e.g. the nanomaterial risk classification system (Tervonen et al. 2009)], generic chemical risk assessment tools (e.g. the European Union System for the Evaluation of Substances [EUSES, Vermeire et al. 1997)] and consumer exposure tools [e.g. CONSEXPO CONSumer EXPOsure and uptake model (van Veen 2001)]. Despite the fact that most of these tools are fundamentally different one from another in terms of scope, aim and methodological approach all are unified by the idea of facilitating robust nano-EHS analyses. However, the general attitude of the interviewees towards these tools can be summarised in the words of one SME respondent: "All the presented tools look very complicated and require expertise to use them. I would like to make a plea for simple tools and for the importance of expert judgement both in industry and in regulatory bodies." SUNDS is envisaged to be an advanced, but easy-to-use and versatile tool, which will hopefully address the needs of its end-users.

\subsubsection{Comparison of tools mentioned by interviewees with available tools}

A review on existing decision analytic tools applied to nanotechnology has been completed to construct a preliminary conceptual model for SUNDS (Subramanian et al. 2014 b). In this section, tools mentioned by the interviewees are compared to decision analytic tools identified through literature review (Subramanian et al. 2014b) to place tools identified by respondents within the broader context of decision analytic tools.

It is important to distinguish decision analytic tools from analytic tools. Decision analytic tools are implements addressed to specific contexts that have explicit analytical and decisional components. An example is control banding (CB) tools where designated hazard and exposure "bands" are integrated within a risk matrix associated with specific risk management measures (RMM). CB tools can facilitate decision-making about RMM that are suitable to particular combinations of hazard and exposure scenarios. In contrast, tools which simply conduct portion(s) of the RA process (e.g. exposure models) without an explicit decisional context (i.e. that compares alternatives) are analytic tools. Subramanian et al. (2014b) retrieved 16 RA tools, 18 LCA tools and 14 MCDA applications for nanotechnology. RA tools can be broadly classified as $\mathrm{CB}$ tools, environmental RA tools and human health RA tools. ${ }^{3}$ Table 2 compares the tools mentioned by the respondents to the categories in Subramanian et al. (2014b). All the tools and frameworks mentioned by industrial and regulatory respondents are reported in separated columns in Table 2, divided according to the categories used in Subramanian et al. (2014b). When a tool or framework belongs to more than one category, this is reported in more than one row in Table 2.

\footnotetext{
3 We reiterate that the literature on analytic tools for RA and LCA of ENM is a different literature, and the focus of Subramanian et al. (2014b) is decision analytic tools.
} 
Respondents in this study mention decision analytic and analytic tools as well as general frameworks and guidelines that they use. They mention decision analytic tools in all categories mentioned in Subramanian et al. (2014b) (i.e. Stoffenmanager nano, Nanoriskcat, Precautionary matrix, LCA tools and MCDA tools are decision analytic tools in Table 2). In general, RA tools are mentioned more often than LCA and MCDA tools. However, among decision analytic tools only $\mathrm{CB}$ tools are mentioned in the category of RA, while mentioned environmental and human health RA tools are analytical. Finally, the LCA tool mentioned (Saling et al. 2002) is not specific to nanotechnology applications and only one MCDA-based tool is mentioned (Tervonen et al. 2009). These findings suggest limited experience with both nanospecific tools, as well as decision analytic tools, and the reasons merit further investigation.

The respondent quote on the use of the tool to identify worst case scenarios may also partially explain the preference for $\mathrm{CB}$ tools. The request for simplicity is also important to note, especially in the light of the following points: (a) complex tools like that based on Bayesian networks (Money et al. 2012) are not mentioned by the respondents, and (b) the sustainable nanotechnology literature advocates the integration of various tools, which can lead to an increase in the complexity of the tool. The trade-off between the sophistication and utility of decision support tool for sustainable nanotechnology needs to be investigated in the future phases of user elicitation.

From the perspective of sustainability analysis, all the mentioned tools except LCA tools contribute only to the environmental pillar of sustainability. SEEBALANCE and AGBALANCE comprise of a LCA-based assessment that includes environmental, economic and social aspects that contribute towards sustainability and are utilised by industry. One regulator respondent mentioned "economic models used by Government Department of Finance and Competition", but details about this tool are not available. The reason for predominance of environmental tools could be that the interview questions focus on the management of risks associated with nanomaterials. The scope of SUNDS is to integrate environmental, economic and social aspects to inform nanomanufacturing decisions, and economic and social assessment will be included as well.

Comparing the mental models of the two types of respondents, regulators mention more tools and frameworks for RA and LCA than the industrial respondents. On the other hand, industrial respondents mention tools related to the management of research, manufacturing, logistics, product safety and company management that are not mentioned by regulators (Table 2). The scope of the lists of regulators and industrialists is dissimilar in the sense that industrialists mention more general management tools. The specificity of the representation of available tools varies per person: some mention specific tools that can be identified in the literature, while others mention unspecified categories of tools, e.g. unspecified LCA and MCDA tools.

\section{Conclusions}

This study is at a scoping level and presents an account on some elements that are taken into account when stakeholders make decisions about risk management of ENM and aim to achieve sustainable nanomanufacturing. The findings presented here are contributing to the development of the SUNDS conceptual framework and methodology. Upcoming rounds of user elicitation will be conducted to finalise the SUNDS conceptual framework and methodology to best address needs of regulatory and industrial users and in addition the insurance sector.

The interviews permit the reconstruction of a social map of the types of organisations involved in such decisionmaking. Within this overall social map, three interconnected "ecosystems" can be distinguished: a political and stakeholder dialogue (cf. Malsch 2014), an industrial value chain and a framework of four regulatory phases: occupational health and safety, chemicals, consumers/retail and environment/waste. These ecosystems are a starting point for designing policy instruments and decision support tools to facilitate collective decision-making on managing the risks associated with nanomaterials.

This study also explores the aspects that are taken into account in regulatory and industrial decision-making. The interviews have led to the development of a list of aspects that are being considered by the SUNDS developers and will be refined at a user workshop in the third round of the study.

Whereas in most decisions on risk management or sustainable manufacturing of nanomaterials software decision support is currently not used, there may be interest in such tools in the future. In order of importance, these tools could be used in supporting compliance with (EU) regulations, supporting internal decision-making on risk management in companies, company internal decision-making on sustainable manufacturing of safe design and supporting policy makers and stakeholders integrating nanomaterials in the international regulatory framework.

Acknowledgments The authors kindly acknowledge the constructive criticism of two anonymous reviewers. The research leading to these results has received funding from the European Union Seventh Framework Programme [FP7/2007-2013] under EC-GA No. 604305 "SUN". This publication reflects the views only of the authors, and the European Commission cannot be held responsible for any use, which may be made of the information contained therein. 
Open Access This article is distributed under the terms of the Creative Commons Attribution License which permits any use, distribution, and reproduction in any medium, provided the original author(s) and the source are credited.

\section{Appendix 1: Questionnaire}

Dear participants,

Please fill in the attached questionnaire and contribute to a key aim of the SUN project: to develop a DSS for practical guidance towards sustainable nanomanufacturing (SUNDS) (see Pert diagram below, SUN DOW part B, p. 19). We-the partners engaged in WP 8, T8.1: Malsch TechnoValuation, University of Venice and University of Limerick-need your ideas and suggestions to help us target this tool to your professional needs and the needs of the companies, research institutes and government bodies you work for. This preliminary questionnaire will help us plan our work in WP 8. In particular, it will contribute to (1) defining the scope of the literature review enabling us to identify a preliminary list of desired SUNDS capabilities and (2) expanding the list of interview candidates through snowballing (the qualitative social science research method). This preliminary questionnaire is distributed to each participant in the kick-off meeting of the SUN project, 29-30 October 2013 and explained during the presentation on WP 8. You can fill in the questionnaire anonymously and the results will only be used within the framework of the SUN project. It is available on paper and online via this link: www.ethicschool.nl/test. Please hand it in by 7 November 2013.

In the coming months, we will furthermore contact you and/or your colleagues for further semi-structured telephone interviews assessing your needs in regard to SUNDS design as input in MS14: a report to be presented and evaluated by the consortium and Advisory Board of the SUN project by March 2014. The study will be conducted in accordance with relevant EU legislation and ethical guidelines including The Charter of Fundamental Rights and Directive 95/46/EC of the European Parliament and of the Council of 24 October 1995 on the protection of individuals with regard to the processing of personal data and on the free movement of such data. If you have any questions regarding this questionnaire, please contact Ineke Malsch.

\section{Questions}

1. What kind of organization do you work for?

- $\mathrm{SME}<250$ employees

- Large industry $>250$ employees
- HEI/public research organization

- Government policy making body (e.g. ministry, European Commission, OECD etc.)

- Authority/notified body/inspectorate etc.

- Other (please specify):

2. What is your position?

- Senior management

- Group leader/middle management

- Researcher

- Other (please specify):

3. Could you briefly describe a decision you have taken regarding producing or using nanomaterials?

4. What information did you need to be able to take this decision? How did you obtain this information? Was the level of information satisfactory for your decision making needs?

5. What criteria did you use to make this decision?

6. How do you assess this decision in retrospect? Could you comment about how your decision making process could be improved?

7. How do you make decisions about technology selection or optimization in producing nanomaterials?

8. Do you use any software tools for technology selection or optimization? If so, what do you use? What kinds of parameters does the software optimize? Are you happy with the support provided by the software?

9. Would you be interested in using a decision support tool? What would you want to use it for? What characteristics should such a tool have in order to be useful for you?

10. Could you suggest companies/research organizations/government bodies that might be interested in using a decision support tool for decisions in manufacturing/using nanomaterials? If possible suggest contact persons for interviews.

11. Please list any references to literature on capabilities for risk assessment decision support tools that you are aware of.

12. Do you have any other comments or suggestions?

Thank you for your cooperation. If you have filled in this questionnaire on paper, please hand it into the organisers during the SUN kick off meeting or send it by post/a scanned copy by e-mail by Friday 7 November 2013 to: Ineke Malsch.

\section{Appendix 2: Questionnaire}

Dear colleague, 
Thank you for agreeing to a semi-structured telephone interview assessing your needs in regard to the design of the SUNDS DSS. Please find attached the indicative list of questions. During the interview I may ask follow-up questions to explore interesting issues that come up. With your permission I will record the interview. This recording will only be used for transcribing the interview and then deleted. I will send you the transcript enabling you to correct errors and/or add clarification after the interview. The transcript will be used as background information for our study and not published as such. Anonymised quotes from the interview may be used in publications. Your responses will be used as input in a report to be presented and evaluated by the consortium and Advisory Board of the SUN project by March 2014. If you are interested, I can send you a pdf of the final report.

The study will be conducted in accordance with relevant EU legislation and ethical guidelines including The Charter of Fundamental Rights and Directive 95/46/EC of the European Parliament and of the Council of 24 October 1995 on the protection of individuals with regard to the processing of personal data and on the free movement of such data. If you have any questions regarding this study, please feel free to ask me.

Kind regards,

Ineke Malsch

\section{General open questions}

1. I have collected some information about your organisation and your function from open sources (see below). Is this correct?

2. What type of decisions regarding nanomaterials and products containing nanomaterials are you involved in?

3. Do you use any software decision support tools? What do you consider the advantages and disadvantages of the tools you use or have heard of?

4. Would you be interested in a new DSS for decisions regarding nanomaterials? If so, what capabilities should this system have? If not, why not?

\section{Specific question industry}

3a. Does your company use decision support tools to guide manufacturing? If so, which tools and how do you use these tools? If not, why not?

3b. [If the user mentions one of the tools the SUN project partners reviewed] Which capabilities/features do you like more?
Insurance-related questions: is there a need for specific risk coverage tools for nanomaterials?

\section{Specific questions regulators}

3b. Does your organisation use decision support tools in risk governance? If so, which tools and how do you use these tools? If not, why not?

5. Please rate from 1 to 10 the value of having the following features in the SUN Decision Support Tool:

Feature

Value $(1=$ low, $10=$ high $)$

Output of risk assessment

Read across approaches to quantitative data on alternatives for research materials with uncertainties and data gaps before investments in scale up

banding approaches to quantitative data on alternatives for research materials with uncertainties and data gaps before investments in scale up

grouping approaches to quantitative data on alternatives for research materials with uncertainties and data gaps before investments in scale up

Quantitative consideration of toxic effects

Quantitative consideration of release rates to human space

Quantitative consideration of release rates to environment

Ecological indicators

Environmental risk management

Open LCA software with specific data and ecoinvent data

Economic indicators

Quantitative consideration of use amounts

Large overview of patents and scientific literature

Societal indicators

Social perceptions of risk

Factors influencing political decisions

Large overview of normative frames

Technical features

Support experimental activity with computational tools

How hazard data can feed into this process and influence output

Easy to use

Online

Sharable with others 


\section{References}

Beaudrie CEH et al (2013) Expert views on regulatory preparedness for managing the risks of nanotechnologies. PLoS ONE 8(11):e80250

Beaudrie CEH, Satterfield T, Kandlikar M, Harthorn BH (2014) Scientists versus regulators: precaution, novelty \& regulatory oversight as predictors of perceived risks of engineered nanomaterials. PLoS ONE 9(9):e106365. doi:10.1371/journal.pone.0106365

Bergeson LL (2013) Sustainable nanomaterials: emerging governance systems. ACS Sustain Chem Eng 1:724-730

Besley John C, Kramer Victoria L, Priest Susanna H (2008) Expert opinion on nanotechnology: risks, benefits, and regulation. J Nanopart Res 10(4):549-558

Black P, Stockton T (2009) Basic steps for the development of decision support systems. In: Marcomini A, Suter GW, Critto A (eds) Decision support systems for risk-based management of contaminated sites (Chapter 1). Springer, New York, pp 1-27

Bridges TS, Kovacs D, Wood MD, Baker K, Butte G, Thorne S, Linkov I (2013) Climate change risk management: a mental modeling application. Environ Syst Decis 33:376-390

Chandrasekharan S, Tovey M (2012) Sum, quorum, tether: design principles underlying external representations that promote sustainability. Pragmat Cogn 20:447-482

Corley EA, Scheufele DA, Hu Q (2009) Of risks and regulations: how leading US nanoscientists form policy stances about nanotechnology. J Nanopart Res 11(7):1573-1585

Dhingra R, Naidu S, Upreti G, Sawhney R (2010) Sustainable nanotechnology: through green methods and life-cycle thinking. Sustainability 2:3323-3338

ECETOC report TR93 (2004) Tiered approach to risk assessment in chemical processes, ECETOC, Brussels. http://www.ecetoc.org/

Eisenman DP, Cordasco KM, Asch S, Golden JF, Glik D (2007) Disaster planning and risk communication with vulnerable communities: lessons from Hurricane Katrina. Am J Public Health 97:S109-S115

Gavankar S, Suh S, Keller AF (2012) Life cycle assessment at nanoscale: review and recommendations. Int J Life Cycle Assess 17:295-303

Hansen SF, Jensen KA, Baun A (2013) NanoRiskCat: a conceptual tool for categorization and communication of exposure potentials and hazards of nanomaterials in consumer products. J Nanopart Res 16:2195

Hischier R, Walser T (2012) Life cycle assessment of engineered nanomaterials: state of the art and strategies to overcome existing gaps. Sci Total Environ 425:271-282

Hollan J, Hutchins E, Kirsh D (2000) Distributed cognition: toward a new foundation for human-computer interaction research. ACM Trans Comput Hum Interact 7(2):174-196

Hristozov DR, Gottardo S, Critto A, Marcomini A (2012) Risk assessment of engineered nanomaterials: a review of available data and approaches from a regulatory perspective. Nanotoxicology 6:880-898

Hutchins E (1995) How a cockpit remembers its speed. Cogn Sci 19:265-288

IRGC (2005) White paper on risk governance, towards and integrative approach, International Risk Governance Council. www.irgc.org

IRGC (2006) White paper on nanotechnology risk governance, International Risk Governance Council. http://www.irgc.org/ IMG/pdf/IRGC_white_paper_2_PDF_final_version-2.pdf, p 57

Jackson D (2013) What is an innovation ecosystem? National Science Foundation, Arlington, VA. http://erc-assoc.org/content/whatinnovation-ecosystem

Jensen KA, Thoustrup Saber A, Vejen Kristensen H, Liguori B, Kalevi Koponen I, Wallin H (2013) NanoSafer vs. 1.1- nanomaterial risk assessment using first order modeling. In: 6th international symposium on nanotechnology, occupational and environmental health, Japan

Jones N, Ross H, Lynam T, Perez P, Leitch A (2011) Mental models: an interdisciplinary synthesis of theory and methods. Ecol Soc $16: 46$

Linkov I, Anklam E, Collier ZA, DiMase D, Renn O (2014) Risk-based standards: integrating top-down and bottom-up approaches. Environ Syst Decis 3(1):134-137. doi:10.1007/s10669-014-9488-3

Malsch I (2014) Nano-education from a European perspective: nanotraining for non-R\&D jobs. Nanotechnol Rev. doi:10.1515/ntrev2013-0039

Malsch I, Subramanian V, Semenzin E, Hristozov D, Marcomini A (pending publication) Collective decision making on risk management and sustainable manufacturing of nanomaterials and the role of decision support tools. In: Proceedings 5th STS Italia conference "a matter of design", 12-14 June 2014, Milan

McDaniels T, Chang S, Cole D, Mikawoz J, Longstaff H (2008) Fostering resilience to extreme events within infrastructure systems: characterizing decision contexts for mitigation and adaptation. Glob Environ Change 18:310-318

Money ES, Reckhow KH, Wiesner MR (2012) The use of Bayesian networks for nanoparticle risk forecasting: model formulation and baseline evaluation. Sci Total Environ. 426:436-445

Morgan K (2005) Development of a preliminary framework for informing the risk analysis and risk management of nanoparticles. Risk Anal 25:1621-1635

Morgan MG, Fischhoff B, Bostrom A, Atman CJ (2002) Risk communication: a mental models approach. Cambridge University Press, Boston

Mulvihill MJ, Beach ES, Zimmerman JB, Anastas PT (2011) Green chemistry and green engineering: a framework for sustainable technology development. Annu Rev Environ Resour 36:271-293

Nanofutures (2012) Integrated research and industry roadmap for european nanotechnology, nanofutures. http://nanofutures.info/ documents

Nanosafety Cluster (2013) European nanosafety cluster compendium of projects 2013 (online document). http://www.nanosafetyclus ter.eu/. Last accessed 29 July 2014

Nanowerk (2014) Nanotechnology company \& research labs directory (online database). http://www.nanowerk.com/nanotechnol ogy/research/nanotechnology_links.php. Last accessed 29 July 2014

Nersessian NJ, Newstetter WC, Kurz-Milcke E, Davies JA (2003) Mixed-method approach to studying distributed cognition in evolving environments. In: Proceedings of the international conference on learning sciences, pp 307-314. http://www.cc. gatech.edu/aimosaic/faculty/nersessian/

ObservatoryNano (2011) European nanotechnology landscape report. ObservatoryNano. http://bwcv.es/assets/2011/11/22/European Nanotechnology_Landscape_Report.pdf

Patenaude J, Legault G-A, Beauvais J, Bernier L, Béland J-P, Boissy P, Chenel V, Daniel C-E, Genest J, Poirier M-S, Tapin D (2014) Framework for the analysis of nanotechnologies' impacts and ethical acceptability: basis of an interdisciplinary approach to assessing novel technologies. Sci Eng Ethics. doi:10.1007/ s11948-014-9543

Porter ME (1985) Competitive advantage: creating and sustaining superior performance. Simon and Schuster, New York

Rauscher H, Roebben G (eds) (2014) Towards a review of the EC recommendation for a definition of the term "nanomaterial". Part 1: compilation of information concerning the experience with the definition. JRC scientific and policy report, Ispra

REACH Regulation Annex XI, ECHA website: http://echa.europa.eu/ web/guest/regulations/reach 
Renn O (2008) Risk governance; coping with uncertainty in a complex world. Earthscan, London

Roncoli C (2006) Ethnographic and participatory approaches to research on farmers' responses to climate predictions. Clim Res 33:81

Saling P, Kicherer A, Dittrich-Krämer B, Wittlinger R, Zombik W, Schmidt I, Schrott W, Schmidt S (2002) Eco-efficiency analysis by BASF: the method. Int J Life Cycle Assess 7:203-218

Schulte PA, McKernan LT, Heidel DS, Okun AH, Dotson GS, Lentz TJ, Geraci CL, Heckel PE, Branche CM (2013) Occupational safety and health, green chemistry, and sustainability: a review of areas of convergence. Environ Health 8:9

Smits RE, Kuhlmann S, Shapira P (eds) (2010) The theory and practice of innovation policy: an international research handbook. Edward Elgar, Northampton

Sterman JD, Sweeney LB (2007) Understanding public complacency about climate change: adults' mental models of climate change violate conservation of matter. Clim Change 80:213-238

Stone-Jovicich SS, Lynam T, Leitch A, Jones NA (2011) Using consensus analysis to assess mental models about water use and management in the Crocodile River catchment, South Africa. Ecol Soc 16:45

Subramanian V, Semenzin E, Hristozov D, Marcomini A, Linkov I (2014a) Sustainable nanotechnology: defining, measuring and teaching. Nano Today 9:6-9
Subramanian V, Semenzin E, Hristozov D, Marcomini A, Linkov I (2014b) Review of decision analytic tools for sustainable nanotechnology. Environ Syst Decis. doi:10.1007/s10669-0159541-x

Tervonen T, Linkov I, Figueira J, Steevens J, Chappell M, Merad M (2009) Risk-based classification system of nanomaterials. J Nanopart Res 11:757-766

Van Duuren-Stuurman B, Vink SR, Verbist KJ, Heussen HG, Brouwer DH, Kroese DE, Tielemans E, Fransman W (2012) Stoffenmanager nano version 1.0: a web-based tool for risk prioritization of airborne manufactured nano objects. Ann Occup Hyg 56(5):525-541

Van Veen MP (2001) Consexpo 3, consumer exposure and uptake models. RIVM report, 612810

Vermeire T, Jager D, Bussian B, Devillers J, Den Haan K, Hansen B, Lundberg I, Niessen H, Robertson S, Tyle H (1997) European union system for the evaluation of substances (EUSES). Principles and structure. Chemosphere 34:1823-1836

Wood MD, Bostrom A, Bridges T, Linkov I (2012a) Cognitive mapping tools: review and risk management needs. Risk Anal 32(8): 1333-1348

Wood M, Kovacs D, Bostrom A, Bridges T, Linkov I (2012b) Flood risk management: US Army Corps of Engineers and layperson perceptions. Risk Anal 32:1349-1368 